Check for updates

Cite this: RSC Adv., 2017, 7, 31907

Received 29th November 2016 Accepted 25th May 2017

DOI: $10.1039 / c 6 r a 27526 e$

rsc.li/rsc-advances

\section{Ionic salt (4-ethoxybenzyl)-triphenylphosphonium bromide as a green corrosion inhibitor on mild steel in acidic medium: experimental and theoretical evaluation}

\author{
Sudershan Kumar, (DD*a Madhusudan Goyal, (D) ${ }^{\text {b }}$ Hemlata Vashisht, ${ }^{c}$ \\ Vandana Sharma, ${ }^{d}$ Indra Bahadur (ID) ${ }^{* e}$ and Eno E. Ebenso (D) ${ }^{\text {e }}$
}

\begin{abstract}
A new phosphonium salt (4-ethoxybenzyl)-triphenylphosphonium bromide (EBTPPB), having different substituents attached to phosphorous and having different anions, is investigated as an inhibitor for mild steel (MS) corrosion in $0.5 \mathrm{M} \mathrm{H}_{2} \mathrm{SO}_{4}$ solutions via electrochemical polarization and electrochemical impedance (EI) spectroscopy. Electrochemical results show that EBTPPB compound has practically good inhibiting features for MS corrosion in the corrosive medium with efficiencies of approximately $98 \%$ at an optimum $10^{-2} \mathrm{M}$ concentration. The inhibition is of a mixed cathodic-anodic type. Passive potential $\left(E_{\mathrm{pp}}\right)$ of the modified steel specimen is in the inactive region and thus inhibits the corrosion process. Langmuir Adsorption (LA) isotherm was performed to provide precise information on the adsorption behavior of the ionic salt. It exhibits both physisorption and predominantly chemisorption mechanism on MS surface. Scanning Electron Microscopy (SEM) associated with Energy Dispersion X-ray (EDX) and Atomic Force Microscopy (AFM) assessment of the electrode surface is consistent with the existence of adsorbing screen of EBTPPB molecules. An apparent connection was ascertained between the experimental corrosion inhibition efficiency (IE\%) and the theoretical parameters using quantum chemical calculations.
\end{abstract}

\section{Introduction}

Corrosion inhibitors reduce the corrosion rate of metallic substances in acidic medium and have been universally applied in case of corrosive attack in crude oil purifier and chemical scratching. ${ }^{1-3}$ There are several classes of inhibitors, e.g. mixed, cathodic and anodic, passivated, precipitators, vapour phase, film forming type and absorbents. ${ }^{4-8}$ There are two processes involved in the action of the corrosion inhibitors: (i) the transfer of the inhibitor to the face of metal and (ii) the chemical interactions of the protector and the metal surface. The adsorption is influenced by the occurrence of a polar group in the inhibitor structure by which the molecules may connect themselves to the surface of the metal. ${ }^{9-12}$ Free electron pairs on

\footnotetext{
${ }^{a}$ Department of Chemistry, Hindu College University of Delhi, Delhi-110007, India. E-mail: sudershankumar@hindu.du.ac.in; Tel: +91-9717952342

${ }^{b}$ Department of Chemistry, University of Delhi, Delhi-110007, India

'Department of Chemistry, Kirori Mal College, University of Delhi, Delhi-110007, India ${ }^{d}$ Department of Environmental Science, Deen Dayal Upadhayaya College, University of Delhi, Delhi-110078, India

${ }^{e}$ Department of Chemistry, School of Mathematical and Physical Sciences, Materials Science Innovation \& Modelling Research Focus Area, Faculty of Agriculture, Science and Technology, North-West University (Mafikeng Campus), Private Bag X2046, Mmabatho 2735, South Africa. E-mail: bahadur.indra@nwu.ac.za
}

heteroatoms or $\pi$ electrons and polar groups containing nitrogen, oxygen, phosphorus and/or sulphur in the molecular structure are fundamental characteristics of good inhibitors. ${ }^{13-16}$ The structure and coverage of the inhibitory molecules both determine their inhibiting ability. ${ }^{17-19}$

The phosphonium compounds belong to the class of ionic salts. ${ }^{20-22}$ The study of various compounds as inhibitors, including ammonium compounds, has been extensively carried out, but the structurally similar group of phosphonium-based ionic salts has not been fully explored. Quaternary phosphonium-based ionic salts are more thermally stable than ammonium and imidazolium-based ionic salts and therefore suitable for high-temperature reactions (up to $200{ }^{\circ} \mathrm{C}$ ). High tunability is the most desirable property of ionic salts whereby on replacing the halide ion with the anionic functional group, several multifunctional ionic salts with numerous useful properties can be generated. ${ }^{16,23-26}$ Quaternary Phosphonium additives show biological properties against macro and microorganisms and have the significant advantage of being "environment-friendly inhibitors". Their benefits include low toxicity, less hazardousness, a rapid breakdown in the environment through biodegradation and hydrolysis, and no or little bioaccumulation. ${ }^{27,28}$ G. Singh et al., synthesized and worked on the anti-corrosion properties of various 
phosphonium compounds such as benzyl triphenyl phosphonium bromide (BTPPB) $)^{7,19}$ and butyl triphenyl phosphonium bromide (BTPB) ${ }^{29}$ for the corrosion of MS in acidic solutions. They also reported possible application of these compounds as green, eco-friendly compounds, which can be used in hydraulic oils and drilling fluids to provide corrosion protection. They improve the corrosion resistance of metals and can be applied to the substrate by immersion or be incorporated in a polymer coating. At the engineering level, their use is not only attributable to their efficiency but also to their safety. ${ }^{20,22,27-31}$ Phosphonium salts are considered as excellent corrosion inhibitors, particularly in acidic media. Khaled ${ }^{32}$ evaluated the inhibiting action of (chloromethyl)triphenyl phosphonium chloride, triphenyl(phenylmethyl)phosphonium chloride and tetraphenyl phosphonium chloride on the corrosion of iron in $1 \mathrm{M} \mathrm{HCl}$ solution. Other authors ${ }^{33}$ tested tetraphenyl phosphonium bromide as nickel corrosion inhibitor in sulfuric acid medium and also evaluated the effect of $\mathrm{R}^{+}, \mathrm{X}^{-}\left(\mathrm{R}^{+}=\left(\mathrm{C}_{8} \mathrm{H}_{17}\right) \mathrm{Ph}_{3} \mathrm{P}^{+}\right.$or $\mathrm{K}^{+}$, $\mathrm{X}^{-}=\mathrm{I}^{-}$or $\mathrm{Br}^{-}$or $\mathrm{Cl}^{-}$) salts' addition on the corrosion of nickel in $1 \mathrm{M} \mathrm{H}_{2} \mathrm{SO}_{4}$ medium. ${ }^{34}$ The results achieved showed that phosphonium iodide addition modifies the interface behaviour due to the interaction between the molecule and the material surface. Tetrahydroxymethyl phosphonium sulfate is a wellknown phosphonium salt that shows biocidal properties against sulfate-reducing bacteria (SRB), which produce sulfuric acid in oil industry. The major drawback of this compound is that it shows very low inhibition efficiency and therefore does not act as good protector against corrosion in the same environment. Therefore, a new phosphonium salt (4-ethoxybenzyl)triphenylphosphonium bromide (EBTPPB), having different substituents attached to phosphorous and having different anions, was investigated as an inhibitor for mild steel (MS) corrosion in $0.5 \mathrm{M} \mathrm{H}_{2} \mathrm{SO}_{4}$ solutions via a variety of techniques such as galvanostatic polarization (GP), potentiostatic polarization (PP), temperature kinetics (TK) and electrochemical impedance (EI) studies. The facade morphology of the MS samples in the absence and presence of ЕBTPPB was investigated using SEM and AFM techniques. The theoretical consideration using quantum chemical calculation was used to corroborate the experimental results obtained.

\section{Experimental}

\subsection{Material test}

Mild steel (MS) rod coupons having composition (wt\%) C = 1.92, $\mathrm{Mn}=0.60, \mathrm{P}=0.17, \mathrm{Si}=0.15$, and remainder $\mathrm{Fe}$, having dimension $1 \mathrm{~cm} \times 1 \mathrm{~cm} \times 3 \mathrm{~cm}(\mathrm{~L} \times \mathrm{B} \times \mathrm{H})$, were employed the as working electrode (WE) for electrochemical measurements. These coupons were accumulated in Araldite glue to facilitate merely $1 \mathrm{~cm}^{2}$ surface region to get in touch with the aggressive media. Before immersing the MS coupon in the respective solutions, it was mechanically polished to obtain a clean and smooth surface through emery papers of different marks i.e. 100, 320, 600, 1000 and 1500. It was mopped up with acetone and swabbed with condensed water to get rid of any particles from the surface.

\subsection{Inhibitor structure and test solution}

The chemical structure of the investigating inhibitor (4ethoxybenzyl)-triphenylphosphonium bromide (ЕВTPPB) is shown in Fig. 1. It was obtained from Sigma-Aldrich Lab product and equipment, India. The corrosive solution was arranged by the strength of methodical $\mathrm{H}_{2} \mathrm{SO}_{4}$ (AR grade, 98\%) with purified water. The different concentrations of EBTPPB (1 $\times 10^{-2} \mathrm{M}$ to $1 \times 10^{-5} \mathrm{M}$ ) employed were prepared in $0.5 \mathrm{M}$ $\mathrm{H}_{2} \mathrm{SO}_{4}$. Before each experiment, a freshly arranged solution was prepared in the research laboratory.

\subsection{Electrochemical measurements}

For corrosion inhibition testing, electrochemical measurements were accomplished using galvanostatic, potentiostatic and AC impedance techniques utilizing $\mathrm{CHI} 760 \mathrm{C}$ electrochemical workspace ( $\mathrm{CH}$ computer instruments, Austin, USA). A three-electrode system was used. MS served as the WE. A platinum foil was exercised the same as an auxiliary electrode (AE). The saturated calomel electrode (SCE) was paired to a luggin capillary pipe whose tilt was placed amid the WE and AE. This three-electrode cell assembly was then kept in a water bath so that the reaction attained a steady-state and/or the open circuit potential (OCP) turned out to be constant. AC impedance results were executed by an AC signal with an amplitude of $10 \mathrm{mV}$ at OCP in the frequency sequence from $10^{5} \mathrm{~Hz}$ to $0.1 \mathrm{~Hz}$. The EIS variants, such as charge transfer resistance $\left(R_{\mathrm{ct}}\right)$ and double layer capacitance $\left(C_{\mathrm{dl}}\right)$, were received from Nyquist spectra. Due to the AC impedance of MS in the presence of a mitigator, the data is made to fit with the corresponding impedance values of an equivalent circuit (EC). The process is performed using the software ZSimpWin Version 3.21. Tafel plots were executed from $298 \mathrm{~K}$ to $328 \mathrm{~K}$ for galvanostatic and at $298 \mathrm{~K}$ for the potentiostatic polarization. The potential range was scanned from $-0.9 \mathrm{~V}$ to $+0.0 \mathrm{~V}$ for galvanostatic and $+0.0 \mathrm{~V}$ to $+2.0 \mathrm{~V}$ for the potentiostatic polarization at the scan rate $0.001 \mathrm{~V} \mathrm{~s}^{-1}$.

\subsection{Surface morphological studies}

Freshly polished MS samples were immersed in $0.5 \mathrm{M} \mathrm{H}_{2} \mathrm{SO}_{4}$ alone and with the addition of $10^{-2} \mathrm{M}$ and $10^{-5} \mathrm{M}$ of ЕВTPPB for $24 \mathrm{~h}$ at a temperature of $25 \pm 2{ }^{\circ} \mathrm{C}$. These were retrieved after $24 \mathrm{~h}$, desiccated and subjected to SEM and AFM analyses. SEM

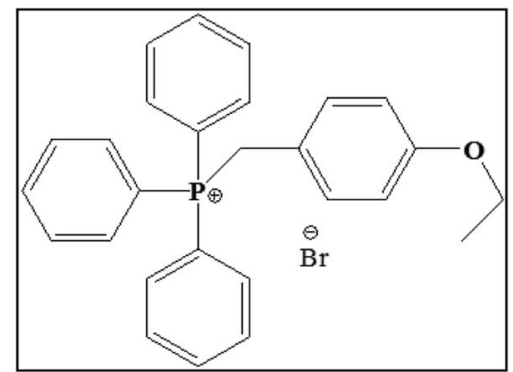

Fig. 1 The molecular structure of (4-ethoxybenzyl)-triphenylphosphonium bromide EBTPPB. 
and AFM measurements were performed using JEOL - JSM 6610 at the accelerating voltage of $20 \mathrm{kV}$ at $5000 \times$ magnification and NAIO AFM Nano-surf easy scan model no. BT-02218 in high vacuum mode, respectively. SEM was correlated with EDX spectroscopy to make clear the nature of MS surface.

\subsection{Temperature kinetic study}

The outcome of temperatures on the decay activities of MS in $0.5 \mathrm{M} \mathrm{H}_{2} \mathrm{SO}_{4}$ with the various concentrations from $10^{-2}$ to $10^{-5} \mathrm{M}$ of EBTPPB was deliberated in the temperature variation of $298-328 \mathrm{~K}$ at a difference of $10 \mathrm{~K}$ with the Langmuir adsorption (LA) isotherm. The noticeable activation energy $\left(E_{\text {act }}\right)$ of the corrosion reaction was determined. Thermodynamic adsorption descriptors such as the equilibrium constant $\left(K_{\text {ads }}\right)$, entropy change $\left(\Delta S_{\text {ads }}^{\circ}\right)$, enthalpy change $\left(\Delta H_{\text {ads }}^{\circ}\right)$, and free energy change $\left(\Delta G_{\text {ads }}^{\circ}\right)$ for adsorption were evaluated to clarify the adsorption behavior of the MS surface.

\subsection{Computational quantum chemical study}

Quantum chemical $(\mathrm{QC})$ calculations were performed via semiempirical AM1 technique since it has proven to be decidedly authentic for computing the physical features of compounds from the software Hyper-Chem 8.0. Computational aspects such as the binding energy, the lowest unoccupied and highest occupied molecular orbital energy ( $E_{\mathrm{LUMO}}$, and $E_{\mathrm{HOMO}}$ respectively), energy gap ( $\left.\Delta E_{\mathrm{L}-\mathrm{H}}=E_{\mathrm{LUMO}}-E_{\mathrm{HOMO}}\right)$, Mulliken's charges, activation hardness $\left(\gamma_{\mathrm{inh}}\right)$ and softness $\left(\sigma_{\mathrm{inh}}=1 / \gamma_{\mathrm{inh}}\right)$, the portion of electrons transferred $\left(\Delta N_{\text {inh }}\right)$ and dipole moment $(\mu)$ were calculated by the geometry optimization of the inhibitor and correlated with protective efficiency.

\section{Results and discussion}

\subsection{Galvanostatic polarization (GP) study}

Tafel polarization lines were recorded for four different concentrations of (4-ethoxybenzyl)-triphenylphosphonium bromide (ЕВTPPB) viz., $\left(\ldots 10^{-5} \mathrm{M}\right),\left(\ldots 10^{-4} \mathrm{M}\right),\left(\ldots 10^{-3} \mathrm{M}\right)$ and $\left(\ldots 10^{-2} \mathrm{M}\right)$ at four temperatures from $298 \mathrm{~K}$ to $328 \mathrm{~K}$ at a difference of $10 \mathrm{~K}$. The solutions were prepared in $0.5 \mathrm{M}$ $\mathrm{H}_{2} \mathrm{SO}_{4}$. Fig. 2(a-d) illustrates the plots of $E$ vs. $\log I$. These significances along with the data of the corrosion current $(I)$, anodic and cathodic Tafel slopes $\left(\beta_{\mathrm{a}} \& \beta_{\mathrm{c}}\right.$, respectively), surface coverage $(\Theta)$ and inhibition efficiency $\left(\mathrm{IE}_{\mathrm{GP}} \%\right)$ are tabulated in Table 1.

Inhibition efficiency (IE\%) was calculated using the expression $^{35}$

$$
\mathrm{IE} \%=\frac{I_{\text {corr }}-I_{\text {corr (inh) }}}{I_{\text {corr }}} \times 100
$$

where $I_{\text {corr }}$ and $I_{\text {corr(inh) }}$ signify the corrosion current density unprotected and protected by EBTPPB inhibitor, respectively.

Surface coverage $(\theta)$ was calculated using

$$
\theta=1-\frac{I_{\text {corr(inh) }}}{I_{\text {corr }}}
$$

At all four temperatures and for all four concentrations of EBTPPB, it was observed that the $I_{\text {corr }}$ decreased compared to that of $0.5 \mathrm{M} \mathrm{H}_{2} \mathrm{SO}_{4}$ alone. The $\mathrm{IE}_{\mathrm{GP}}(\%)$, as given in Table 1, rose with the increase in the concentration of EBTPPB but decreased with a move up in temperature. It signifies that EBTPPB molecules are adsorbed on the surface of MS at higher concentrations, leading to greater $\theta$. A comparison of $\mathrm{IE}_{\mathrm{GP}}(\%)$ values of EBTPPB with BTPPB $^{36}$ revealed that EBTPPB exhibits better corrosion inhibition potentials than BTPPB over the concentration and temperature ranges considered in this study. This higher inhibition and adsorption are attributed to the existence of aromatic rings and conjugated $\pi$ electrons and ethoxy $\left(-\mathrm{OCH}_{2} \mathrm{CH}_{3}\right)$ as electron donating group, which serve as adsorption positions for their interaction with the MS surface.

The lopsided values of cathodic and anodic Tafel slopes indicate that two different types of mechanisms are involved in the inhibitory action of EBTPPB on the corrosion of MS surface. This could be (a) adsorption of EBTPPB molecules on the MS surface, thereby creating a boundary on the MS surface which separates it from the surroundings and (b) the synergistic effect offered by some other anions like bromide $\left(\mathrm{Br}^{-}\right)$ions present in the solution. Since, the inhibition efficiency is observed to be higher at higher concentrations of ЕBTPPB, it can be construed that molecules of EBTPPB get adsorbed on the surface of MS almost entirely. ${ }^{37}$

The corrosion potential values $\left(E_{\text {corr }}\right)$ do not swing much from the corresponding value of MS in $0.5 \mathrm{M} \mathrm{H}_{2} \mathrm{SO}_{4}$. When the change in $E_{\text {corr }}> \pm 85 \mathrm{mV} / \mathrm{SCE}$ compared to $E_{\text {acid }}$, the mitigator may be judged to be anodic or cathodic in nature. When the shift in $E_{\text {corr }}< \pm 85 \mathrm{mV} / \mathrm{SCE}$, the corrosion mitigator can be observed the same as a mixed model. However, in the present case, the potential displacement is less than $50 \mathrm{mV} / \mathrm{SCE}$, which authenticates that EBTPPB performs as a mixed nature of inhibitor. $^{38,39}$

\subsection{Electrochemical impedance spectroscopy (EIS)}

From the characterization of simple electrode processes for analysis of very complex interfaces, a method that has gained much relevance and popularity in recent times is now known as Electrochemical Impedance Spectroscopy (EIS). The most critical applications that can be studied using EIS are for testing corrosion, researching batteries and numerous other surface treatments, e.g., coating, etc. ${ }^{40,41} \mathrm{An}$ attempt is made to investigate the performance of an ionic salt EBTPPB compound as an inhibitor of corrosion for MS using impedance spectra. Nyquist and Bode spectra of MS in sulfuric acid with and without various concentrations of EBTPPB are specified in Fig. 3(a) and (b), respectively, and data observed from these spectra are tabulated in Table 2.

The inhibition efficiency was obtained using the following expression (eqn (3)):

$$
\eta_{\mathrm{EIS}}(\%)=\left(\frac{R_{\mathrm{ct}(\mathrm{inh})}-R_{\mathrm{ct}(\text { acid })}}{R_{\mathrm{ct}(\mathrm{inh})}}\right) \times 100
$$

where $R_{\text {ct(inh) }}$ denotes the charge transfer inhibited resistance and $R_{\text {ct(acid) }}$ specifies the charge transfer resistance in the 

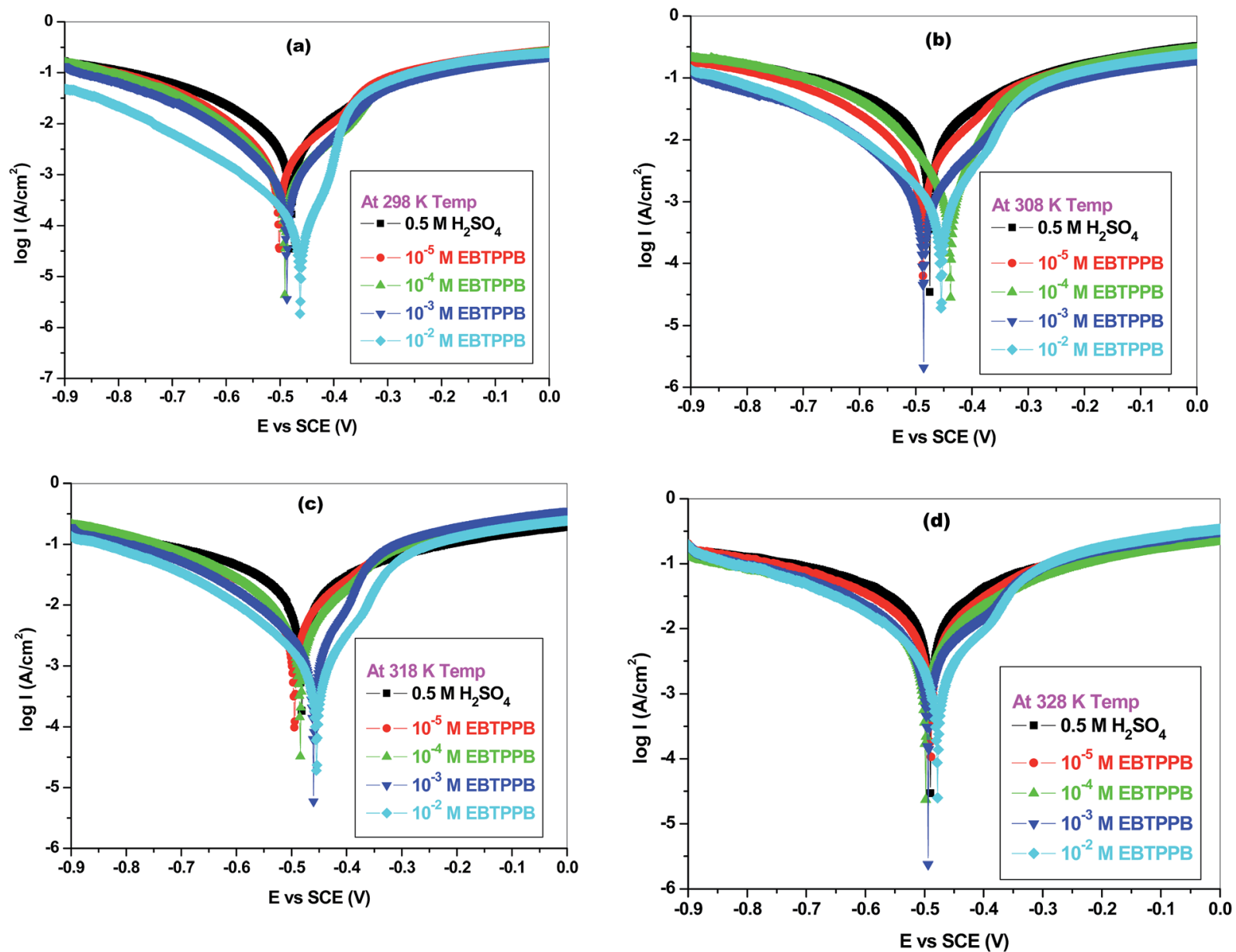

Fig. 2 Tafel polarisation curves for MS in $0.5 \mathrm{M} \mathrm{H}_{2} \mathrm{SO}_{4}$ containing different concentrations of EBTPPB at temperatures (a) $298 \mathrm{~K}$, (b) $308 \mathrm{~K}$, (c) 318 $\mathrm{K}$, and (d) $328 \mathrm{~K}$.

Table 1 Corrosion parameters of MS in $0.5 \mathrm{M} \mathrm{H}_{2} \mathrm{SO}_{4}$ in the presence of EBTPPB

\begin{tabular}{|c|c|c|c|c|c|c|c|}
\hline Temp. (K) & Conc. (M) & $-E_{\text {corr }}(\mathrm{mV})$ & $\beta_{\mathrm{c}}\left(\mathrm{mV} \mathrm{dec}{ }^{-1}\right)$ & $\beta_{\mathrm{a}}\left(\mathrm{mV} \mathrm{dec}{ }^{-1}\right)$ & $I_{\text {corr }}\left(\mathrm{mA} \mathrm{cm}^{-2}\right)$ & IE $(\%)$ & $\Theta$ \\
\hline \multirow[t]{4}{*}{298} & $\mathrm{H}_{2} \mathrm{SO}_{4}$ & 465 & 164.2 & 141.6 & 8.8050 & - & - \\
\hline & $10^{-5}$ & 501 & 120.7 & 108.3 & 1.8601 & 78.87 & 0.7887 \\
\hline & $10^{-3}$ & 487 & 110.1 & 96.99 & 0.6881 & 92.18 & 0.9218 \\
\hline & $10^{-2}$ & 483 & 114.2 & 138.2 & 0.1619 & 98.16 & 0.9816 \\
\hline \multirow[t]{3}{*}{308} & $\mathrm{H}_{2} \mathrm{SO}_{4}$ & 475 & 189.3 & 168.8 & 14.990 & - & - \\
\hline & $10^{-3}$ & 486 & 122.9 & 111.7 & 1.2031 & 91.97 & 0.9197 \\
\hline & $10^{-2}$ & 501 & 150.8 & 129.6 & 0.0206 & 98.62 & 0.9862 \\
\hline \multirow[t]{4}{*}{318} & $\mathrm{H}_{2} \mathrm{SO}_{4}$ & 481 & 208.1 & 196.4 & 16.390 & - & - \\
\hline & $10^{-5}$ & 495 & 175.6 & 145.0 & 7.5831 & 53.73 & 0.5373 \\
\hline & $10^{-4}$ & 484 & 153.6 & 114.1 & 5.0210 & 69.36 & 0.6936 \\
\hline & $10^{-3}$ & 460 & 130.5 & 98.25 & 1.4470 & 91.17 & 0.9117 \\
\hline & $10^{-3}$ & 494 & 157.9 & 149.5 & 5.0231 & 72.44 & 0.7244 \\
\hline & $10^{-2}$ & 478 & 153.6 & 105.6 & 2.5380 & 86.07 & 0.8607 \\
\hline
\end{tabular}



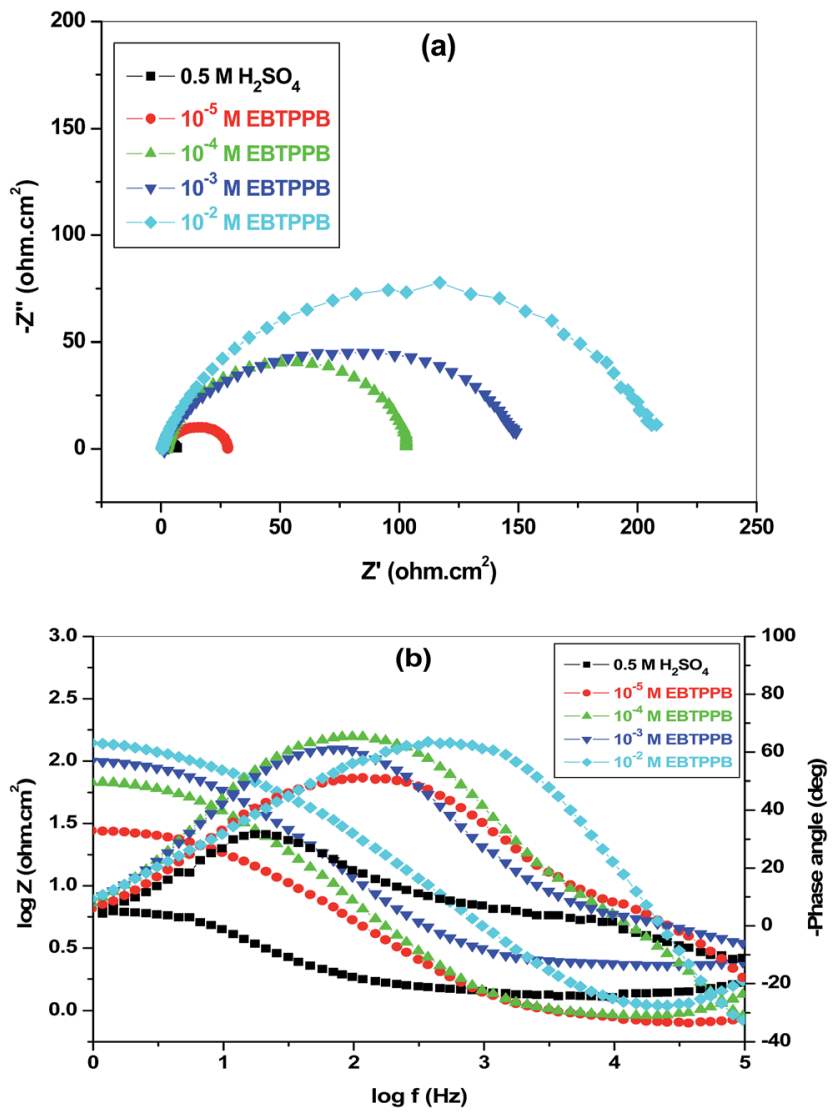

Fig. 3 Impedance plots for $\mathrm{MS}$ in $0.5 \mathrm{M} \mathrm{H}_{2} \mathrm{SO}_{4}$ and in the presence of various concentrations of EBTPPB at $298 \mathrm{~K}$. (a) Nyquist plot, and (b) Bode plot.

Table 2 EIS data for $\mathrm{MS}$ in $0.5 \mathrm{M} \mathrm{H}_{2} \mathrm{SO}_{4}$ in the absence and presence of different concentrations of inhibitor EBTPPB

\begin{tabular}{llclll}
\hline Solutions & $\begin{array}{l}\text { Concentration } \\
(\mathrm{M})\end{array}$ & $R_{\mathrm{ct}}\left(\Omega \mathrm{cm}^{2}\right)$ & $C_{\mathrm{dl}}\left(\mu \mathrm{F} \mathrm{cm} \mathrm{cm}^{-2}\right)$ & $f_{\max }$ & IE $(\%)$ \\
\hline $\mathrm{H}_{2} \mathrm{SO}_{4}$ & 0.5 & 4.954 & 15935 & 2.017 & - \\
$\mathrm{EBTPPB}$ & $10^{-5}$ & 28.26 & 554.5 & 10.16 & 82.47 \\
& $10^{-4}$ & 103.2 & 37.87 & 40.74 & 95.19 \\
& $10^{-3}$ & 173.4 & 20.17 & 45.52 & 97.14 \\
& $10^{-2}$ & 221.8 & 10.88 & 66.02 & 97.77
\end{tabular}

existence of acid solution alone. The value of $R_{\mathrm{ct}}$ was estimated by subtracting the value of solution resistance $\left(R_{\mathrm{S}}\right)$ from the polarization resistance $\left(R_{\mathrm{p}}\right)$ for MS in each solution. The values of the latter quantities were obtained from the Nyquist plots. The intercept on the $x$-axis (real impedance (Re(Imp))) gives the value of $R_{\mathrm{S}}$, and the end point on the same axis gives the value of $R_{\mathrm{p}}$. The value of charge transfer resistance is then calculated using eqn (4):

$$
R_{\mathrm{ct}}=R_{\mathrm{p}}-R_{\mathrm{s}}
$$

The double layer capacitance, $C_{\mathrm{dl}}$ is also calculated using the following relation (eqn (5)): ${ }^{42}$

$$
C_{\mathrm{dl}}=\frac{1}{2 \pi f_{\max } R_{\mathrm{ct}}}
$$

where, $f_{\max }$ represents the frequency where the imaginary fraction of the impedance, i.e., $Z^{\prime \prime}$ has upper limit magnitude.

Impedance spectra in the Nyquist plot have a semicircle loop and the span of the semicircle is enhanced with improving the inhibitor concentrations of EBTPPB. The single capacitive loop indicates that a charge transfer process principally controls the rust of MS. Moreover, the AC impedance spectrum contains a depressed semicircle, which indicates the surface heterogeneity due to roughness, fractal structures, inhibitor's adsorption and distribution of activity centers. The EIS results for EBTPPB on MS surface are simulated by an equivalent circuit (EC) revealed in Fig. 4(c) obtained in accordance with the data fitting curve illustrated in Fig. $4(\mathrm{a}$ and $\mathrm{b})$ with a $\chi^{2}$ value of 3.15 $\times 10^{-4}$. The superiority of fitting to EC was reviewed by chisquare value. The small value of $\chi^{2}$ indicates a better fit. ${ }^{26,43,44}$

As seen from Table 2, it is apparent that the $R_{\mathrm{ct}}$ data are enhanced by enhancing the concentration $(0.00001$ to $0.01 \mathrm{M})$ of EBTPPB, signifying that the corrosion rate declines. $C_{\mathrm{dl}}$ values reduce with the accumulation of ЕВTPРB, resulting in a reduction in the dielectric constant $\left(\varepsilon_{0}\right)$ and a rise in the wideness of the electrical double shield layer, recommending the creation of the shielding layer on the Fe surface. ${ }^{45}$

\subsection{Potentiostatic polarization study (PPS)}

Research was executed on the transition of MS rod from active to the passive region in the corrosive medium. It was observed that the active-passive transformation was an auto-catalytic route in which a pre-passive layer develops on the sample surface. Passive screen functions as a blockade, inhibiting the oxidation reaction (Fe dissolution) at the anodic regions. This inhibition mechanism was usually recognized as metal/MS passivation also noticed in the inhibited system ЕВТРPB. ${ }^{46,47}$

The potentiostatic action of the anodic dissolution of MS in the acidic standard in the occurrence of various concentrations $\left(10^{-2}\right.$ to $\left.10^{-5} \mathrm{M}\right)$ of EBTPPB was investigated, and the anodic dissolution parameters such as critical current $\left(I_{\mathrm{c}}\right)$, passive potential $\left(E_{\mathrm{pp}}\right)$, passive current $\left(I_{\mathrm{p}}\right)$ were obtained from Fig. 5 and reported in Table 3. $I_{\mathrm{c}}$ was seen to decrease with increasing concentrations of EBTPPB. The values of $I_{\mathrm{p}}$ were also inferior compared with dissolution in ЕBTPPB alone. The passivation range is the highest at $558-1652 \mathrm{mV}$ for the lower concentration of EBTPPB, which suggests that EBTPPB molecules get adsorbed at a lower concentration $\left(10^{-5} \mathrm{M}\right)$ on the MS surface. The mechanism followed is that of adsorption of $(\mathrm{M}-\mathrm{Ln})_{\text {ads }}$ molecules as well as the synergistic effect offered by the bromide ion. EBTPPB works as an excellent passivator on MS surface in $0.5 \mathrm{M}$ $\mathrm{H}_{2} \mathrm{SO}_{4}$.

\subsection{Scanning electron microscopy (SEM)}

To examine the surface morphology and acquire an apparent understanding of the nature of adsorptions, scanning electron micrographs were recorded. Fig. 6(a) shows SEM images of polished bare MS surface, which is free from any pits and 

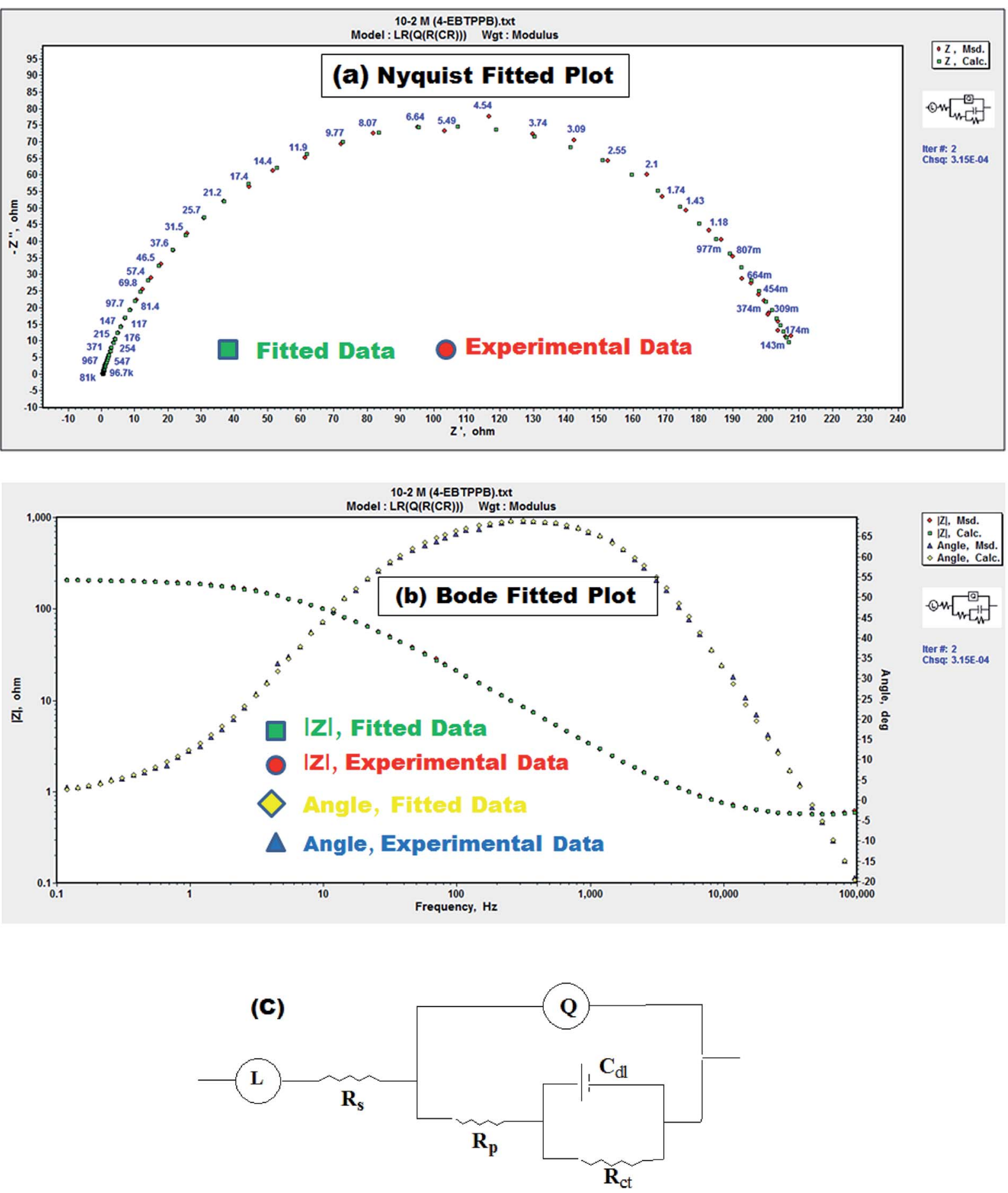

Fig. 4 (a) Nyquist fitting, (b) Bode fitting and (c) equivalent circuit corresponding to experimental data ( $\mathrm{MS}$ in $0.5 \mathrm{M} \mathrm{H}_{2} \mathrm{SO}_{4}$ in the presence of $10^{-2} \mathrm{M}$ of EBTPPB).

cracks. Fig. 6(b) displays the damaged surface and the formation of corrosion products i.e. $\mathrm{FeO}_{2}$ on the $\mathrm{MS}$ surface in the corrosive medium. Fig. 6(c and d) illustrates the morphology of the MS surface after corrosion in the presence of the EBTPPB. This is evident from the micrographs that the corrosion of MS in the acid media was inhibited substantially in comparison with those in the absence of ЕВTPPB.
SEM reveals that less corrosion occurred on the MS surface at the time the concentration of additive was $1 \times 10^{-2} \mathrm{M}$ for ЕВТРPB. This may happen due to the involvement of $\pi$-electrons present due to conjugation in the phenyl rings. The benzyl group and the phenyl rings seem to blanket the facade of MS in the presence of EBTPPB as an inhibitor as the percentage of carbon is more on the surface. More corrosion is viewed on the 


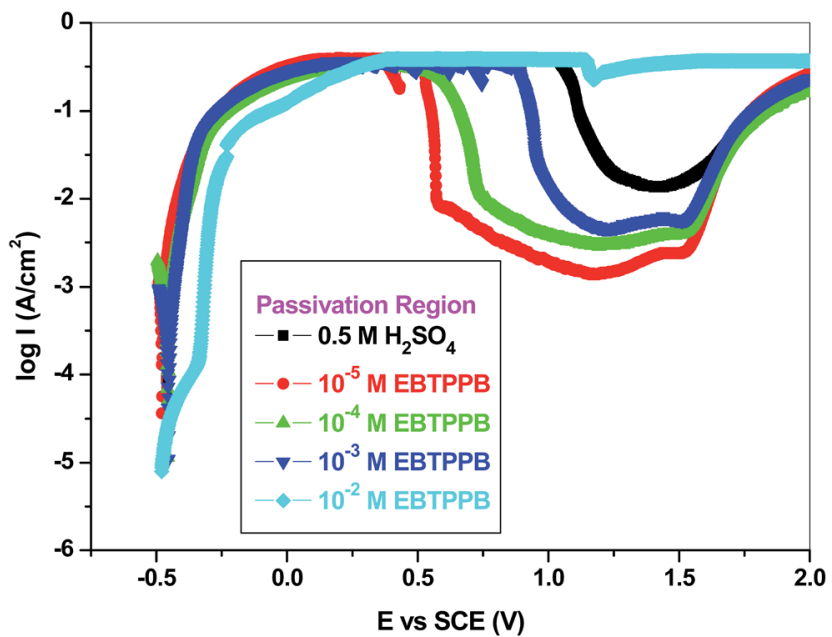

Fig. 5 Potentiostatic polarisation curves for MS in $0.5 \mathrm{M} \mathrm{H}_{2} \mathrm{SO}_{4}$ containing different concentrations of EBTPPB at $298 \mathrm{~K}$.

Table 3 Polarisation parameters for anodic dissolution of MS in $0.5 \mathrm{M}$ $\mathrm{H}_{2} \mathrm{SO}_{4}$ in the presence of EBTPPB

\begin{tabular}{lllll}
\hline Solutions & $\begin{array}{l}\text { Concentration } \\
(\mathrm{M})\end{array}$ & $I_{\mathrm{c}}\left(\mathrm{mA} \mathrm{cm}^{-2}\right)$ & $I_{\mathrm{p}}\left(\mathrm{mA} \mathrm{cm}^{-2}\right)$ & $E_{\mathrm{pp}}(\mathrm{mV})$ \\
\hline $\mathrm{H}_{2} \mathrm{SO}_{4}$ & 0.5 & 376.0 & 35.1 & $1377-1552$ \\
EBTPPB & $10^{-5}$ & 235.4 & 9.04 & $558-1652$ \\
& $10^{-4}$ & 269.6 & 21.5 & $607-1611$ \\
& $10^{-3}$ & 356.3 & 29.2 & $1098-1547$ \\
& $10^{-2}$ & - & - & -
\end{tabular}

sample surface when the concentration of the additive is trimmed down to $1 \times 10^{-5} \mathrm{M}$. Its scrutiny also reports the high inhibition efficiency values achieved during the polarization studies of the EBTPPB inhibitory system. ${ }^{48,49}$

\subsection{Energy dispersive X-ray spectroscopy (EDX)}

EDX spectroscopy presents the significance of the intensity and composition of the areas on the MS coupons regarding atomic percent. ${ }^{50,51}$ EBTPPB has been investigated as the inhibitor of corrosion of MS. As a shred of evidence for its potential to inhibit corrosion of MS in acidic medium, the energy dispersive spectra of MS surface is recorded in $10^{-2} \mathrm{M}$ and $10^{-5} \mathrm{M}$ of EBTPPB. The EDX spectra demonstrated in Fig. 7(a-d) correspond to the SEM in Fig. 6(a-d), and the related information in terms of atomic percent is reported in Table 4.

The spectra in Fig. 7(b) show the peak for iron (Fe) and oxygen (O), signifying the formation of iron oxide/hydroxide on the surface of the MS sample. The spectra of inhibited specimens $\{$ Fig. 7 (c and d) $\}$ that facilitated the Fe lines were noticeably suppressed when judged against the polished (Fig. 7(a)) and uninhibited (Fig. 7(b)) spectra of MS surface. Inhibition of Fe lines was because of the inhibitory shield that existed on the MS surface. The (\%) atomic content of Fe for MS in $0.5 \mathrm{M} \mathrm{H}_{2} \mathrm{SO}_{4}$ solution is $54.91 \%$ and those for MS dipped in an optimum
$10^{-2} \mathrm{M}$ (higher) and $10^{-5} \mathrm{M}$ (lower) concentration of ЕВTPPB are $77.13 \%$ and $68.64 \%$, respectively. These results specified that the MS surface was coated with the protective shape of EBTPPB molecules. The composition of the MS surface explained that the adsorption of EBTPPB protected the corrosion through $\pi$-electron conjugated in aromatic phenyl rings and benzyl group attached with electron donating group. EDX with SEM analysis offered a powerful indication for the existence of EBTPPB protective coating over the MS surface.

\subsection{Atomic force microscopy (AFM)}

AFM serves as a potent tool for the examination and characterization of a variety of samples from nanometer to micrometer length scales..$^{52,53}$ The AFM image of the abraded surface (Fig. 8(a)) of the MS without any pre-treatment with sulphuric acid and the inhibitor compound was obtained first. Then, three other MS samples were prepared by immersing them in $0.5 \mathrm{M}$ sulphuric media uninhibited and inhibited in $1 \times 10^{-2} \mathrm{M}$ and $1 \times 10^{-5} \mathrm{M}$ concentrations of ЕВTPPB for 24 hour, and images were recorded at a temperature of $298 \mathrm{~K}$.

The Fig. 8(b) clearly shows the extent of corrosion in the presence of sulphuric acid. Deep pits and cracks were seen, which showed the degree of surface damage. The MS surface could be quantitatively analyzed by evaluating the roughness of metal surface (RMS) area. The value of the RMS in sulphuric acid is $668.2 \mathrm{~nm}$. The higher value of RMS in the presence of $0.5 \mathrm{M} \mathrm{H}_{2} \mathrm{SO}_{4}$ signifies the greater extent of corrosion. The Fig. 8(c) indicates that the MS surface was shielded with $10^{-2} \mathrm{M}$ of EBTPPB inhibitor molecules giving it a large extent of protection in opposition to corrosion, thereby decreasing the RMS value to $111.1 \mathrm{~nm}$. As the number of inhibitory molecules decreased in $10^{-5} \mathrm{M}$ of EBTPPB solution, the MS surface was protected to a lesser extent as can be assured from Fig. 8(d), and the RMS value increased to $188.4 \mathrm{~nm}$ in comparison to the value obtained with $10^{-2}$ M EBTPPB solutions. RMS values through the AFM study of the metal surface authenticated the existence of adsorption barriers of EBTPPB.

\subsection{Adsorption isotherm and temperature kinetic effect}

The adsorption isotherm confers an insight into the adsorption mechanism and perception on the metal-inhibitor relations and can be ascribed from the curve of surface coverage rate aligned with the inhibitor concentrations. To investigate the adsorption procedure of EBTPPB on MS, respective adsorption isotherms were trialled for the explanation of the adsorption mechanism. ${ }^{54}$ The value of correlation constant $\left(R^{2}\right)$ obtained in the plots of $C / \theta$ versus $C$ (Fig. 9) equal to or close to 1 indicates that Langmuir adsorption (LA) isotherm is followed by a particular adsorption process at an appropriate temperature. The following equation (eqn (6)) represents the adsorption isotherm relationship for Langmuir adsorption isotherm: $:^{55}$

$$
\frac{C_{\mathrm{inh}}}{\theta}=\frac{1}{K_{\mathrm{ads}}}+C_{\mathrm{inh}}
$$

where $C_{\mathrm{inh}}$ denotes the EBTPPB defender concentration of reaction, $\theta$ represents the coverage of the treatment on the 

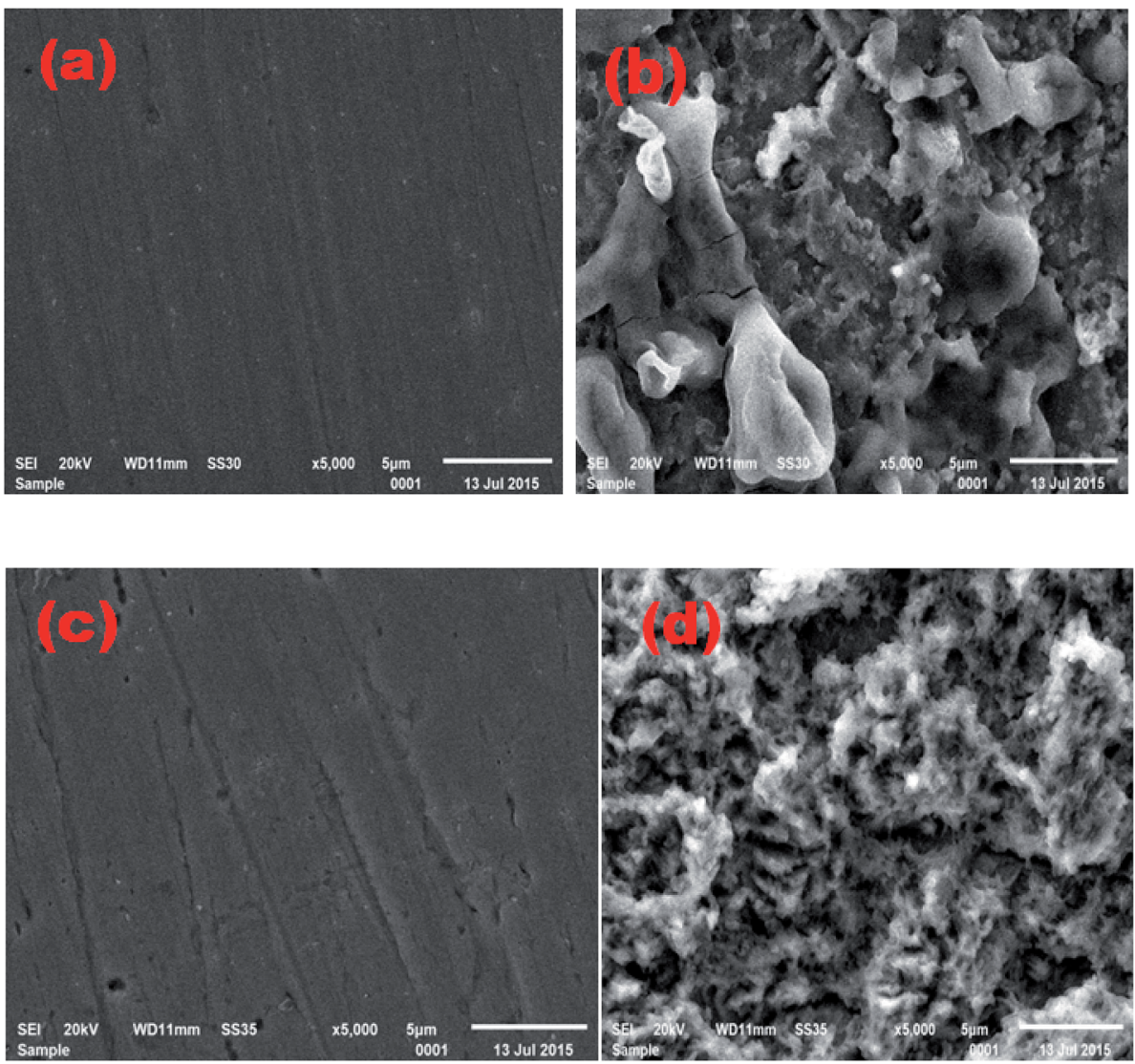

Fig. 6 SEM images of (a) plain MS surface, (b) MS in $0.5 \mathrm{M} \mathrm{H}_{2} \mathrm{SO}_{4}$, (c) MS in $0.5 \mathrm{M} \mathrm{H}_{2} \mathrm{SO}_{4}+10^{-2} \mathrm{M} \mathrm{EBTPPB}$, (d) $\mathrm{MS}$ in $0.5 \mathrm{M} \mathrm{H} \mathrm{SO}_{4}+10^{-5} \mathrm{M}$ EBTPPB, after $24 \mathrm{~h}$ exposure at the $\times 5000$ magnification.

metal surface, which can be obtained from the $\% \mathrm{IE}_{\mathrm{GP}} / 100$ ratio, where $\mathrm{IE}_{\mathrm{GP}}(\%)$ is obtained from the Tafel polarization method (see Table 1 ). $K_{\text {ads }}$ signifies the equilibrium secure for the adsorption rule. The significant extent value of $K_{\text {ads }}$ indicates the high adsorption capacity of ЕBTPPB defender on the MS surface.
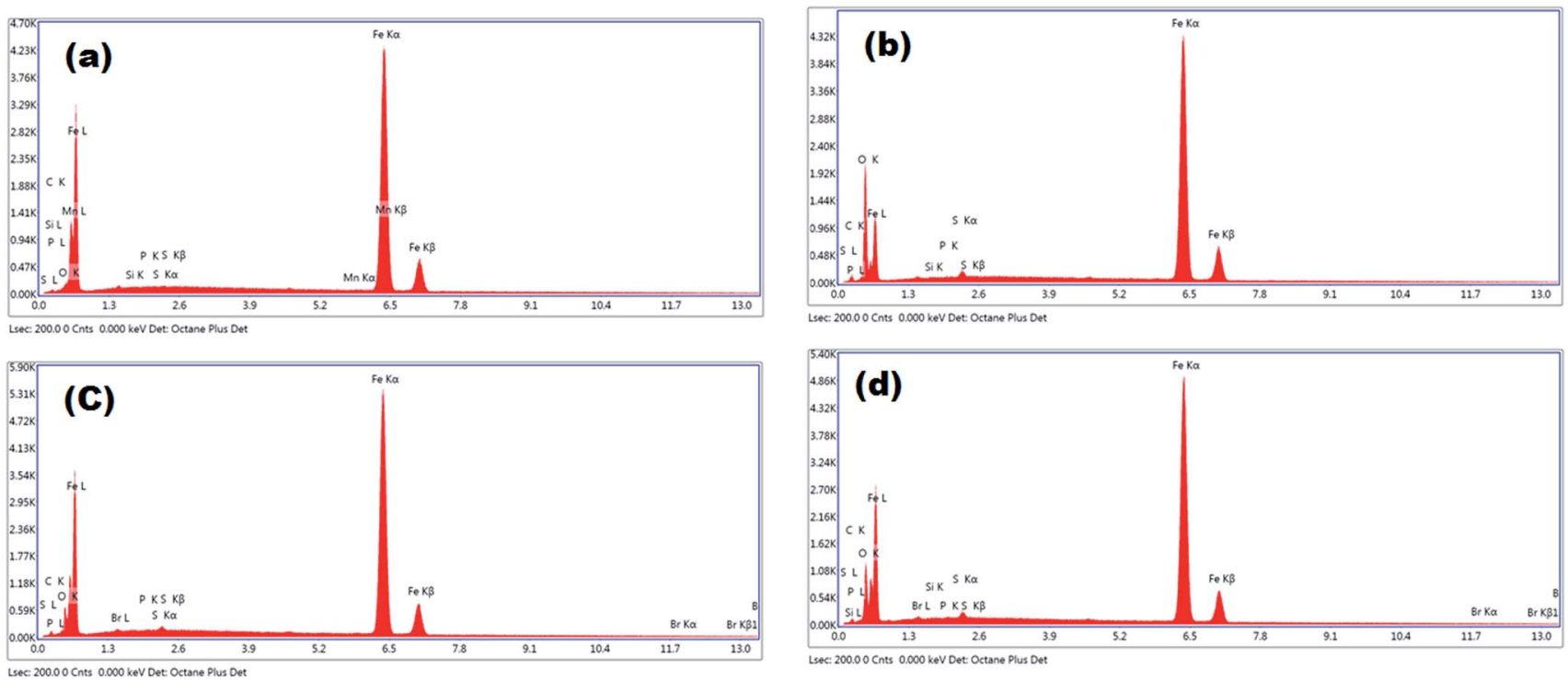

Fig. 7 EDXS spectra of (a) plain MS surface, (b) MS in $0.5 \mathrm{M} \mathrm{H}_{2} \mathrm{SO}_{4}$, (c) $\mathrm{MS}$ in $0.5 \mathrm{M} \mathrm{H}_{2} \mathrm{SO}_{4}+10^{-2} \mathrm{M} \mathrm{EBTPPB}$, (d) $\mathrm{MS}$ in $0.5 \mathrm{M} \mathrm{H}_{2} \mathrm{SO}_{4}+10^{-5} \mathrm{M}$ EBTPPB. 
Table 4 EDX data for MS in $0.5 \mathrm{M} \mathrm{H}_{2} \mathrm{SO}_{4}$ in the absence and presence of different concentrations of inhibitor EBTPPB

\begin{tabular}{lcccccr}
\hline Solutions & $\mathrm{Fe}$ & $\mathrm{O}$ & $\mathrm{S}$ & $\mathrm{P}$ & $\mathrm{Br}$ & \multicolumn{1}{c}{$\mathrm{C}$} \\
\hline Plain mild surface & 86.02 & 4.470 & 0.25 & 0.28 & - & 8.02 \\
$0.5 \mathrm{M} \mathrm{H}_{2} \mathrm{SO}_{4}$ & 54.91 & 32.01 & 0.79 & 0.15 & - & 11.94 \\
$10^{-5} \mathrm{M} \mathrm{EBTPPB}^{-2} \mathrm{M} \mathrm{EBTPPB}_{10}$ & 77.64 & 18.86 & 1.03 & 0.22 & 0.27 & 11.41 \\
& & 10.46 & 0.63 & 0.34 & 0.14 & 10.12
\end{tabular}

The $K_{\text {ads }}$ is interrelated to the change in free energy of adsorption $\left(\Delta G_{\text {ads }}^{\circ}\right)$ according to the following relation:

$$
\Delta G_{\mathrm{ads}}^{\circ}=-R T \ln \left(55.5 K_{\mathrm{ads}}\right)
$$

where $R$ denotes ideal gas constant $\left(8.314 \mathrm{~J} \mathrm{~mol}^{-1} \mathrm{~K}^{-1}\right), T$ represents temperature and $\mathbf{5 5 . 5}$ fixed quantity of the concentration of $\mathrm{H}_{2} \mathrm{O}$.
The change in enthalpy of adsorption $\left(\Delta H_{\mathrm{ads}}^{\circ}\right)$ was calculated via the Van't Hoff equation.

$$
\ln K_{\mathrm{ads}}=\frac{-\Delta H_{\mathrm{ads}}^{\circ}}{R T}+\text { const. }
$$

Enthalpy values were worked out from the slope $\left(-\Delta H_{\text {ads }}^{\circ} / R\right)$ of the scheme of the natural logarithm of $K_{\mathrm{ads}}$ versus $1 / T$, which is depicted in Fig. 10 and tabulated in Table 5.

The values of $\Delta G_{\text {ads }}^{\circ}$ and $\Delta H_{\text {ads }}^{\circ}$ obtained from eqn (7) and (8), respectively, can now be substituted in eqn (9) to calculate the entropy of the adsorption process using the following equation:

$$
\Delta G_{\mathrm{ads}}^{\circ}=\Delta H_{\mathrm{ads}}^{\circ}-T \Delta S_{\mathrm{ads}}^{\circ}
$$

On rearrangement of eqn (9), we get eqn (10) as follows:
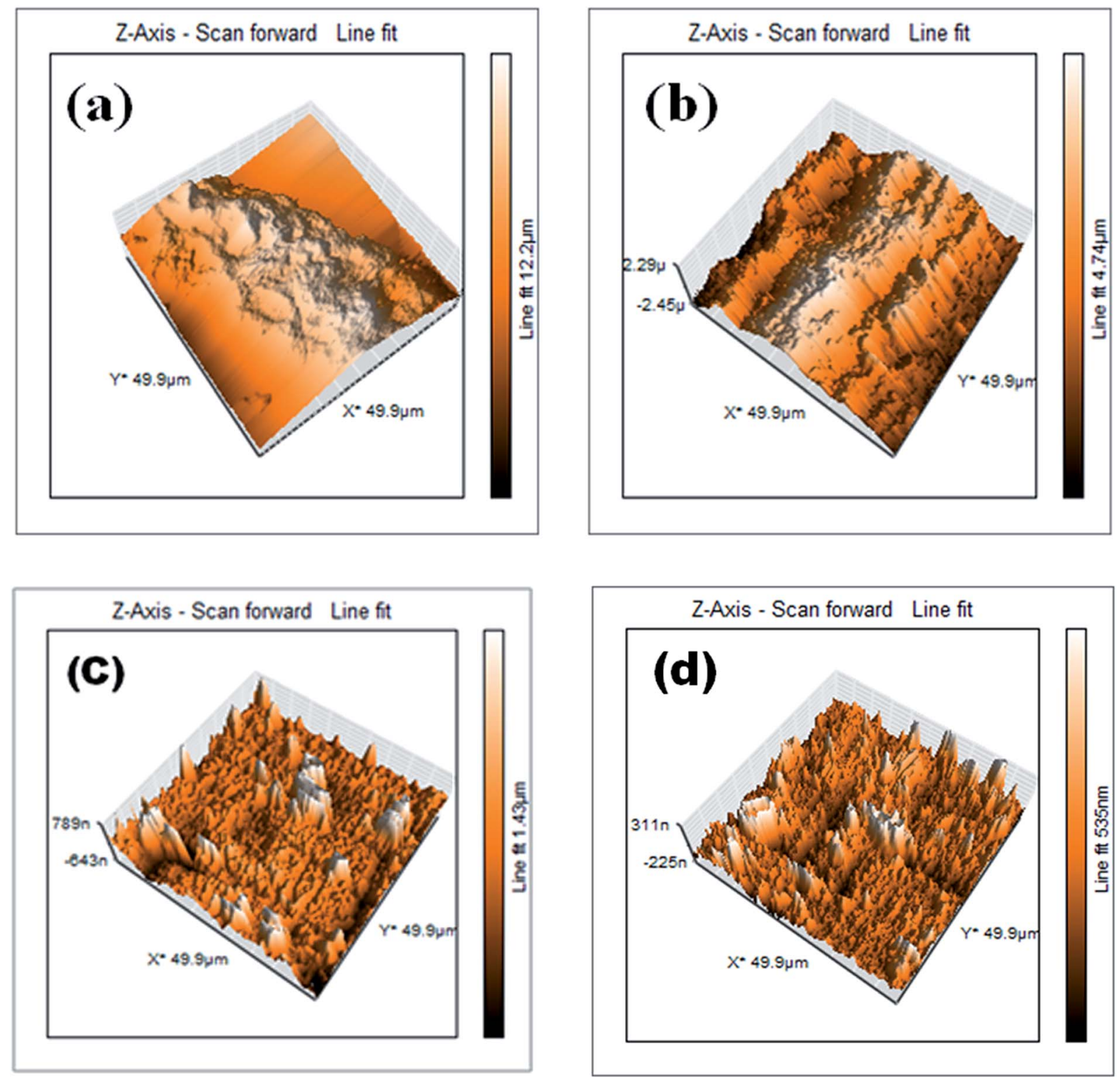

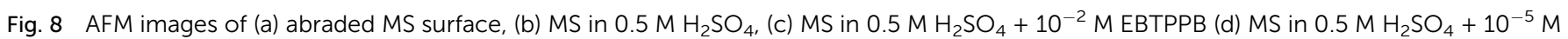
EBTPPB. 


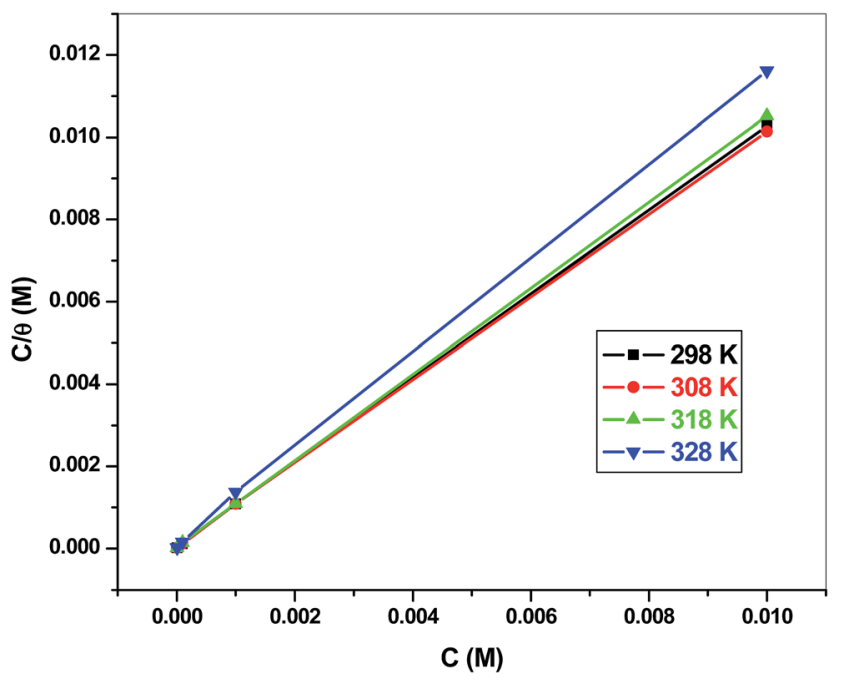

Fig. 9 Representative Langmuir's adsorption isotherms for MS at different temperatures.

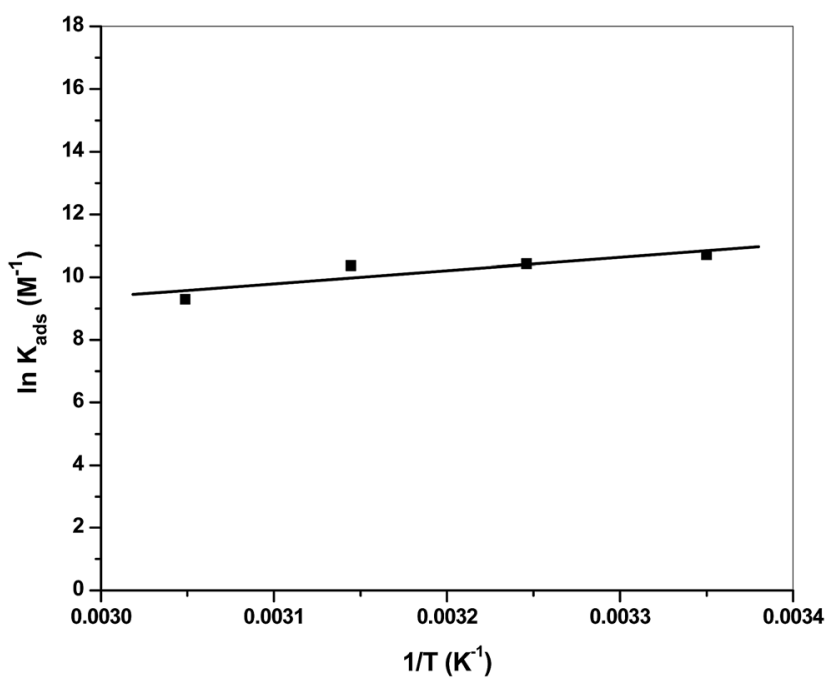

Fig. 10 In $K_{\text {ads }}$ versus $1 / T$ plot for corrosion of EBTPPB inhibited MS in $0.5 \mathrm{M} \mathrm{H}_{2} \mathrm{SO}_{4}$.

$$
\Delta S_{\mathrm{ads}}^{\circ}=\frac{\Delta H_{\mathrm{ads}}^{\circ}-\Delta G_{\mathrm{ads}}^{\circ}}{T}
$$

The thermodynamic parameters achieved from LA isotherm for EBTPPB are reported in Table 5. The mitigating mechanism is customarily clarified with the creation of a physically and/or chemically type adsorbed shield on the sample. The assessments of $(-) \Delta G_{\text {ads }}^{\circ}$ signify a spontaneous adsorption practice and strength of the adsorbed barrier of the protector for the sample face. Usually, when $\Delta G_{\text {ads }}^{\circ}$ is approximately $-20 \mathrm{~kJ}$ $\mathrm{mol}^{-1}$, the type of adsorption is considered to be a physical adsorption, while when $\Delta G_{\text {ads }}^{\circ}$ is approximately $-40 \mathrm{~kJ} \mathrm{~mol}^{-1}$ or lesser, the type of adsorption is considered to be a chemical adsorption. The $\Delta G_{\text {ads }}^{\circ}$ values in the current research exist from -36.4 to $-38.9 \mathrm{~kJ} \mathrm{~mol}^{-1}$, which indicate that the adsorption of EBTPPB molecules allows chemisorptions to dominate. The negative values of $\Delta S_{\text {ads }}^{\circ}$ for EBTPPB inhibitor indicated that the activated compound in the rate determining measure characterizes an association more than a dissociation action, indicating that a reduction in chaos takes place from the substrate through the intermediate to the (Fe/EBTPPB) activated complex. Generally, for physisorption, $\Delta H_{\mathrm{ads}}^{\circ}$ is lesser than $40 \mathrm{~kJ} \mathrm{~mol}^{-1}$, whereas for chemisorption approaches, it is $100 \mathrm{~kJ} \mathrm{~mol}^{-1}$. The absolute $\Delta H_{\text {ads }}^{\circ}$ assessed for adsorption of EBTPPB was $44.78 \mathrm{~kJ}$ $\mathrm{mol}^{-1}$, which was higher than $40 \mathrm{~kJ} \mathrm{~mol}^{-1}$ and indicated that the adsorption of inhibitor employed was exothermic, and chemisorption took place predominantly. ${ }^{56-58}$

\subsection{Activation energy}

Activation descriptors have a significant role in recognizing the inhibiting mechanism. The galvanostatic polarization study (Table 1) was completed in the range of 298-323 K temperature using several concentrations of EBTPPB ionic salt inhibitor in $0.5 \mathrm{M} \mathrm{H}_{2} \mathrm{SO}_{4}$ for MS. The activation energy ( $\left.E_{\text {act }}\right)$ associated with current rate can be expressed via the Arrhenius relation ${ }^{59}$

$$
\log \left(I_{\text {corr }}\right)=\log A-\left(-E_{\text {act }} / 2.303 R T\right)
$$

where $I$ refers to the corrosion rate and $A$ stands for the preexponential Arrhenius constant. Fig. 11(a) characterizes the Arrhenius plot of $\log I$ against $1 / T(\mathrm{~K})$ for the oxidization of MS in $0.5 \mathrm{M} \mathrm{H}_{2} \mathrm{SO}_{4}$ solutions without or with the presence of EBTPPB at a level ranging from $10^{-5} \mathrm{M}$ to $10^{-2} \mathrm{M}$. In Fig. 11(a), the slope of every linear fit line is specified, and $E_{\text {act }}$ is computed $\left\{E_{\text {act }}=2.303 \times R \times\right.$ (slope) $\}$. A graph shown in Fig. 11(b) is plotted between the activation energy and various concentrations of the inhibitor EBTPPB. Scrutiny of Table 6 reveals that $E_{\text {act }}$ values are not too high except at $10^{-2} \mathrm{M}$ concentration for the inhibited medium (ЕВTPPB + acid) than uninhibited medium (acid alone), demonstrating a comprehensive route (physisorption and chemisorption) of adsorption action. The active barrier is slighter low, easing the formation of $\mathrm{Fe}^{2+}$ ions,

\begin{tabular}{|c|c|c|c|c|}
\hline $\begin{array}{l}\text { Temperature } \\
(\mathrm{K})\end{array}$ & $K_{\text {ads }} \times 10^{4} \mathrm{M}^{-1}$ & $-\Delta G_{\mathrm{ads}}^{\circ}\left(\mathrm{kJ} \mathrm{mol}^{-1}\right)$ & $-\Delta H_{\mathrm{ads}}^{\circ}\left(\mathrm{kJ} \mathrm{mol}^{-1}\right)$ & $-\Delta S_{\text {ads }}^{\circ}\left(\mathrm{J} \mathrm{K}^{-1} \mathrm{~mol}^{-1}\right)$ \\
\hline 298 & 4.4325 & 36.459 & & 27.92 \\
\hline 308 & 3.3658 & 36.978 & 44.78 & 25.33 \\
\hline 318 & 3.1843 & 38.032 & & 21.22 \\
\hline 328 & 1.0932 & 36.312 & & 25.81 \\
\hline
\end{tabular}

Table 5 Adsorption parameters at different temperatures studied for EBTPPB 

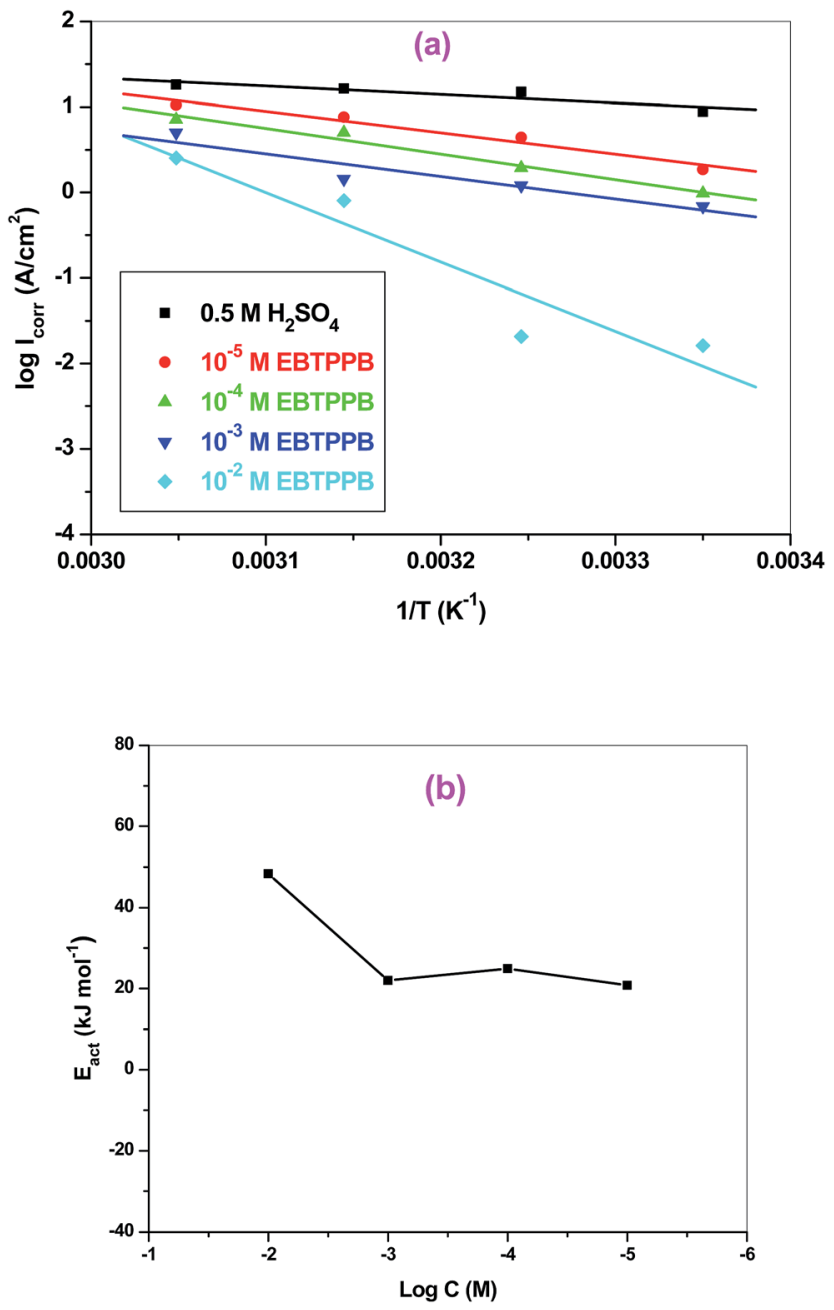

Fig. 11 (a) Arrhenius plot for $\mathrm{MS}$ in $0.5 \mathrm{M} \mathrm{H}_{2} \mathrm{SO}_{4}$ without and with various concentrations of EBTPPB, (b) plot of activation energy vs. inhibitor concentrations.

which act together with the EBTPPB ionic salt to appear as a protective shape. ${ }^{60}$

\subsection{Quantum chemical calculation (QCC)}

Computational chemistry is not only operated as a viewing tool to examine several chemical compounds but also prominently to modernize an understanding of the behaviour of the various coordinations as a function of their structural characteristics. ${ }^{61-63}$ The optimized geometry and Mulliken's charges are

Table 6 Activation parameters for the corrosion of MS in the presence and absence of EBTPPB

\begin{tabular}{ll}
\hline Concentration $(\mathrm{M})$ & $E_{\mathrm{a}}\left(\mathrm{kJ} \mathrm{mol}^{-1}\right)$ \\
\hline $0.5 \mathrm{M} \mathrm{H}_{2} \mathrm{SO}_{4}$ & 18.93 \\
$10^{-5}$ & 20.75 \\
$10^{-4}$ & 24.89 \\
$10^{-3}$ & 21.96 \\
$10^{-2}$ & 48.54
\end{tabular}

given in Fig. 12(a) and (b). Fig. 12(c) and (d) give the 3-D isosurface map of $E_{\text {Номо }}$ and $E_{\mathrm{LUMO}}$, respectively. The various optimized AM1 parameters for EBTPPB are reported in Table 7 and associated with their inhibitor effectiveness.

As indicated by the Frontier molecular (FM) orbital speculation, ${ }^{64,65}$ the pattern of an intermediate position is an outcome of relations among the FM orbital (LUMO and HOMO) of reactants. The $E_{\text {LUMO }}-E_{\text {Hомо }}(\Delta E)$ gap is an essential stability key. A small LUMO - HOMO energy gap leads to high experimental protective efficiency and stability of the protector in chemical reactions. In the present research, EBTPPB inhibitor has the lowest $\Delta E$ value $7.3774 \mathrm{eV}$, which assists its adsorption on the MS surface. ${ }^{66}$

The concepts of activation hardness $\left(\gamma_{\mathrm{inh}}\right)$ and softness $\left(\sigma_{\mathrm{inh}}\right)$ have also been defined by the LUMO - HOMO energy space. To justify this, the following formula was used: ${ }^{67,68}$

$$
\begin{gathered}
\gamma_{\text {inh }}=\frac{E_{\mathrm{LUMO}}-E_{\mathrm{HOMO}}}{2} \\
\sigma_{\mathrm{inh}}=\frac{1}{\gamma_{\text {inh }}}
\end{gathered}
$$

where $\sigma_{\text {inh }}$ and $\gamma_{\text {inh }}$ are the attributes to assess the compound stability and reactivity. Soft compounds are more reactive than hard ones since these may attract electron donor to acceptors promptly. The soft molecule has small energy space and large space is present in the hard ones. From our current computational evaluation (Table 7), we find that EBTPPB possesses $\gamma_{\text {inh }}$ of $3.690 \mathrm{eV}$ and $\sigma_{\text {inh }}$ of $0.2710 \mathrm{eV}$, which conforms with the experimental statistics of mitigation efficiency.

The number of transferred electrons $\left(\Delta N_{\text {inh }}\right)$ from the EBTPPB protector to MS sample surface was also computed using the following relation: ${ }^{69}$

$$
\begin{gathered}
\Delta N_{\mathrm{inh}}=\frac{\chi_{\mathrm{Fe}}-\chi_{\mathrm{inh}}}{2\left(\gamma_{\mathrm{inh}}+\gamma_{\mathrm{Fe}}\right)} \\
\chi_{\mathrm{inh}}=-\frac{E_{\mathrm{LUMO}}+E_{\mathrm{HOMO}}}{2}
\end{gathered}
$$

To evaluate the $\Delta N_{\text {inh }}$, hypothetical data of the electronegativity of $\mathrm{Fe}, \chi_{\mathrm{Fe}}$ nearly equal to $7 \mathrm{eV} \mathrm{mol}^{-1}$, and $\gamma_{\mathrm{Fe}}=0 \mathrm{eV} \mathrm{mol}^{-1}$ and calculated $E_{\text {Hомо }}(-7.8164 \mathrm{eV})$ and $E_{\text {LuMO }}(-0.4340 \mathrm{eV})$ were used for EBTPPB (see Table 7). As stated by Awad's study, ${ }^{70}$ when the $\Delta N_{\text {inh }}$ value was less than 3.6, the mitigation efficiency improved with enhanced electron-releasing power at the surface of the sample. The value of $\Delta N_{\text {inh }}$ (0.3893) signifies the number of electrons departing from the donor and going into the acceptor molecule. ${ }^{67}$ An enhancement in electron donating capability was evinced by electron donating substituent $\left(-\mathrm{OCH}_{2} \mathrm{CH}_{3}\right.$ group attaches with benzyl group), which enlarges the protection efficiency. It may be insisted that EBTPPB has a high ability to adsorb on the MS surface.

The confined electron densities or charges are necessary for understanding the physicochemical properties of molecules. Mulliken charge scrutiny is frequently applied for the computation of the charge circulation in the structure. From the Mulliken charge densities and analysis, more negatively 

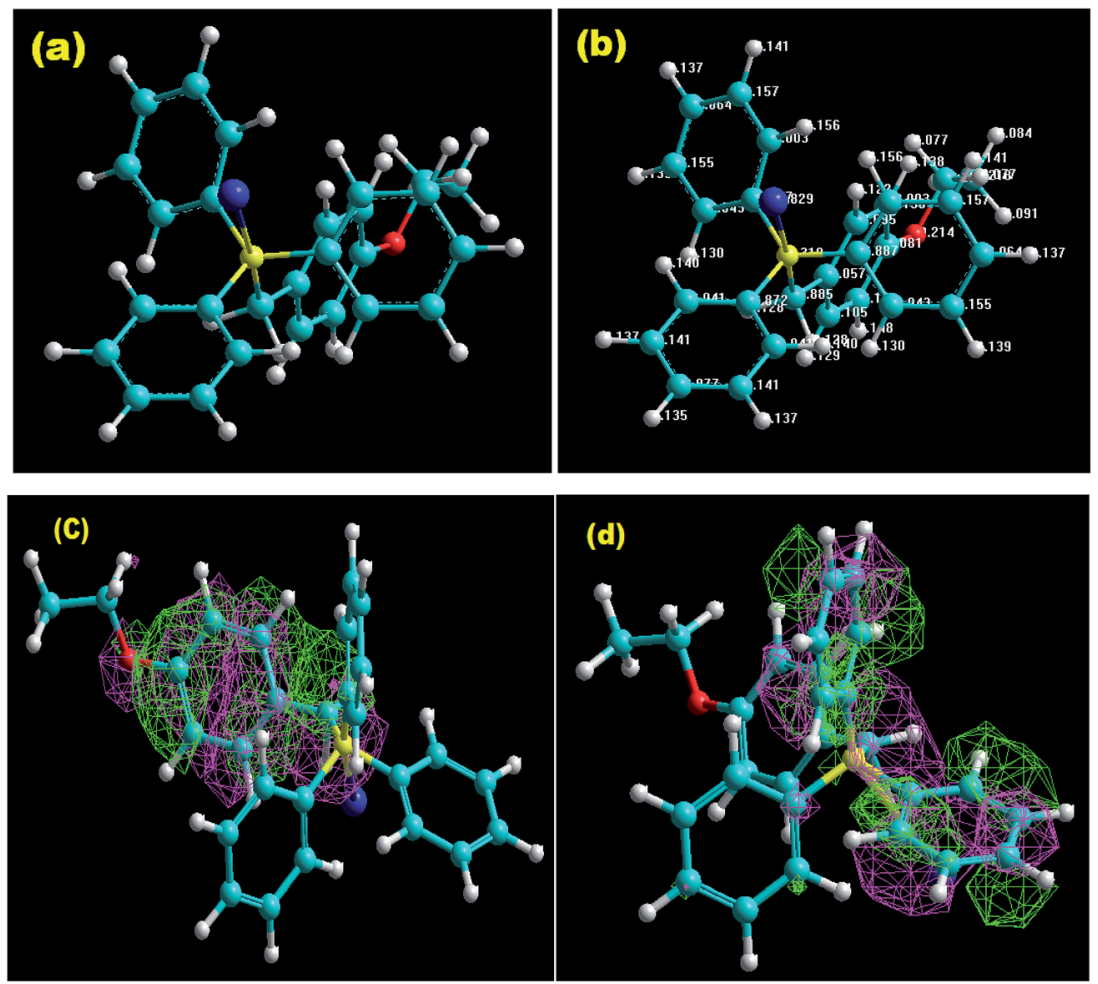

Fig. 12 Computed quantum parameters for EBTPPB: (a) ball and stick optimized structure, (b) Mulliken charges, (c) HOMO Frontier orbital energy distribution, and (d) LUMO Frontier orbital energy distribution.

Table 7 Quantum chemical parameters of EBTPPB using AM $_{1}$ semiempirical method, Hyper Chem. 8.0

\begin{tabular}{ll}
\hline Total energy $\left(\mathrm{kcal} \mathrm{mol}^{-1}\right)$ & -106439 \\
Energy of HOMO $(\mathrm{eV})$ & -7.8164 \\
Energy of LUMO $(\mathrm{eV})$ & -0.4340 \\
Energy gap $\left(\Delta E_{\mathrm{L}-\mathrm{H}}\right)$ & 7.3824 \\
Binding energy $\left(\mathrm{kcal} \mathrm{mol}{ }^{-1}\right)$ & -6096.5 \\
Softness $(\sigma) \mathrm{eV}$ & 0.2710 \\
Global hardness $(\gamma) \mathrm{eV}$ & 3.6887 \\
Number of transfer electron $\left(\Delta N_{\mathrm{inh}}\right)$ & 0.3893
\end{tabular}

charged atoms act as an active focal point, which can be adsorbed through donor-acceptor type of reaction on the surface of metal. It is observed from Fig. 12(b) that the charge on central phosphorous atom 3.39 and negative charges in the region of the carbons atoms of the aromatic rings, methylene carbon, oxygen, and bromide are adsorption active centers. The EBTPPB ionic salt is adsorbed on the MS surface using these active sites, facilitating the corrosion mitigation action..$^{71-73}$

The smallest the total energy value $\left(-106439 \mathrm{kcal} \mathrm{mol}^{-1}\right)$ is the ground state energy of the coordination. The binding energy of the inhibitor EBTPPB was found to be negative $(-6096 \mathrm{kcal}$ $\mathrm{mol}^{-1}$ ), which advocated that the inhibitor was stable and less prone to divide. There is a possibility of interaction of $\pi$-electrons of EBTPPB with the MS surface, thereby retarding the corrosion rate because EBTPPB is a polar molecule as indicated by it dipole moment value $(7.63 \mu){ }^{45}$

\section{Conclusions}

The systematic study of corrosion inhibition of MS was carried out in $0.5 \mathrm{M} \mathrm{H}_{2} \mathrm{SO}_{4}$ using various concentrations of an ionic salt (4-ethoxybenzyl)-triphenylphosphonium bromide (ЕВTPPB) from 298 to $328 \mathrm{~K}$ temperatures. The outcomes of these studies can be concluded as follows:

- Inhibition efficiency of green ionic salt enhances on enhancing the inhibitory concentration $\left(10^{-5}\right.$ to $\left.10^{-2} \mathrm{M}\right)$, and protection takes places with adsorption of the EBTPPB inhibitor on the MS surface. The adsorption of mitigator is confirmed by the Langmuir adsorption (LA) isotherm.

- The EIS results demonstrate that $R_{\mathrm{ct}}$ values enhance with increasing the protector concentration, while the values of $C_{\mathrm{dl}}$ reduce with escalating the protector concentration.

- The best fit of the curves has been found from their corresponding equivalent circuits. The small value of $\chi^{2}$ indicates better fit curves.

- SEM with EDX investigation of the surface confirmed the presence of films and adsorption of ЕВTPPB inhibitor on the MS surface.

- AFM study revealed that the extent of roughness decreased when the concentrations of EBTPPB were increased from $10^{-5} \mathrm{M}$ to $10^{-2} \mathrm{M}$.

- QC calculations were accomplished to sustain the adsorption mechanism with the molecular structure of EBTPPB. 


\section{Acknowledgements}

The authors acknowledge the Hindu College, and the University of Delhi, India for providing infrastructure and lab facilities. Dr Sudershan Kumar also thanks the Department of Science and Technology, New Delhi (SERB) funding the research project (grant no. SB/EMEQ-217/2013). Prof I. Bahadur is thankful to NRF/DST and North-West University South Africa for funding.

\section{References}

1 Y. Ma, F. Han, Z. Li and C. Xia, ACS Sustainable Chem. Eng., 2016, 4, 633-639.

2 M. A. Hegazy, A. Y. El-etre, M. El-shafaie and K. M. Berry, J. Mol. Liq., 2016, 214, 347-356.

3 P. J. Ramakrishnan, V. Deth, K. Janardhanan, R. Sreekumar and K. P. Mohan, Int. J. Corros., 2014, 2014, 1-5.

4 W. Furbeth and M. Schutze, Mater. Corros., 2009, 60, 481-494.

5 Y. Duda, R. Govea-rueda, H. I. Beltra and L. S. Zamudiorivera, J. Phys. Chem. B, 2005, 109, 22674-22684.

6 A. K. Dewan, D. P. Valenzuela and S. T. Dubey, Ind. Eng. Chem. Res., 2002, 41, 914-921.

7 H. Vashisht, I. Bahadur, S. Kumar, K. Bhrara, D. Ramjugernath and G. Singh, Int. J. Electrochem. Sci., 2014, 9, 2896-2911.

8 G. Boisier, A. Lamure, N. Pébère, N. Portail and M. Villatte, Surf. Coat. Technol., 2009, 203, 3420-3426.

9 S. S. Shivakumar and K. N. Mohana, Int. J. Corros., 2013, 2013, 1-13.

10 C. Jeyaprabha, S. Sathiyanarayanan and G. Venkatachari, J. Electroanal. Chem., 2005, 583, 232-240.

11 H. M. A. El-lateef, A. M. Abu-dief and B. E. M. El-gendy, J. Electroanal. Chem., 2015, 758, 135-147.

12 M. A. Migahed, A. M. Abdul-Raheim, A. M. Atta and W. Brostow, Mater. Chem. Phys., 2010, 121, 208-214.

13 J. Saranya, M. Sowmiya, P. Sounthari, K. Parameswari, S. Chitra and K. Senthilkumar, J. Mol. Liq., 2016, 216, 42-52.

14 A. A. Farag, A. S. Ismail and M. A. Migahed, J. Mol. Liq., 2015, 211, 915-923.

15 E. E. Ebenso, D. A. Isabirye and N. O. Eddy, Int. J. Mol. Sci., 2010, 11, 2473-2498.

16 R. E. Ramírez, L. C. Torres-González and E. M. Sánchez, J. Electrochem. Soc., 2007, 154, B229.

17 D. Mercier and M. G. Barthés-Labrousse, Corros. Sci., 2009, 51, 339-348.

18 A. Popova, M. Christov and A. Zwetanova, Corros. Sci., 2007, 49, 2131-2143.

19 K. Bhrara and G. Singh, Appl. Surf. Sci., 2006, 253, 846-853.

20 F. Atefi, M. T. Garcia, R. D. Singer and P. J. Scammells, Green Chem., 2009, 11, 1595-1604.

21 M. L. Wang, B. L. Liu and S. J. Lin, J. Chin. Inst. Chem. Eng., 2007, 38, 451-459.

22 C. Jangu and T. E. Long, Polymer, 2014, 55, 3298-3304.

23 A. Popova, M. Christov and A. Vasilev, Corros. Sci., 2015, 94, 70-78.

24 X. Zheng, S. Zhang, W. Li, M. Gong and L. Yin, Corros. Sci., 2015, 95, 168-179.
25 J. Saien, M. Kharazi and S. Asadabadi, J. Mol. Liq., 2015, 212, 58-62.

26 M. S. Morad, Corros. Sci., 2000, 42, 1307-1326.

27 W. Wehner and R. Grade, Canadian Patent No. CA2082994, 1993.

28 S. Kobase, H. Takerchi and M. Sumita, Japanese Patent No. JP2000316701, 2000.

29 K. Bhrara, H. Kim and G. Singh, Corros. Sci., 2008, 50, 27472754.

30 A. M. El-Shamy, K. Zakaria, M. A. Abbas and S. Zein El Abedin, J. Mol. Liq., 2015, 211, 363-369.

31 S. M. Taw, J. Mol. Liq., 2016, 216, 624-635.

32 K. F. Khaled, Appl. Surf. Sci., 2004, 230, 307-318.

33 S. O. Niass, M. E. Touhami, N. Hajjaji, A. Srhiri and H. Takenouti, J. Appl. Electrochem., 2001, 31, 85-92.

34 F. Said, N. Souissi, A. Dermaj, N. Hajjaji, E. Triki and A. Srhiri, Mater. Corros., 2005, 56(9), 619-623.

35 S. M. A. Hosseini, M. Quanbari and M. Salari, Indian J. Chem. Technol., 2007, 14, 376-381.

36 M. J. Bahrami, S. M. A. Hosseini and P. Pilvar, Corros. Sci., 2010, 52, 2793-2803.

37 H. Vashisht, I. Bahadur, S. Kumar, G. Singh, D. Ramjugernath and E. E. Ebenso, Int. J. Electrochem. Sci., 2014, 9, 5204-5221.

38 E. S. Ferreira, C. Giacomelli and F. C. Giacomelli, Mater. Chem. Phys., 2004, 83, 129-134.

39 M. Yadav, S. Kumar and D. Sharma, Surf. Rev. Lett., 2013, 20, 1350057-1350075.

40 A. K. Manohar, O. Bretschger, K. H. Nealson and F. Mansfeld, Bioelectrochemistry, 2008, 72, 149-154.

41 A. K. Satpati, M. M. Palrecha and R. I. Sundaresan, Indian J. Chem. Technol., 2008, 15, 163-167.

42 M. Abdallah and B. A. A. L. Jahdaly, Int. J. Electrochem. Sci., 2015, 10, 2740-2754.

43 J. R. Xavier, S. Nanjundan and N. Rajendran, Ind. Eng. Chem. Res., 2012, 51, 30-43.

44 S. Şafak, B. Duran, A. Yurt and G. Türkoĝlu, Corros. Sci., 2012, 54, 251-259.

45 H. Vashisht, S. Kumar, I. Bahadur and G. Singh, Int. J. Electrochem. Sci., 2014, 9, 684-699.

46 M. A. Amin, S. S. Abd El-Rehim and M. N. Abbas, Arabian J. Chem., 2011, 4, 135-145.

47 M. Walia and G. Singh, Surf. Eng., 2005, 21, 176-179.

48 J. Alam, U. Riaz and S. Ahmad, Curr. Appl. Phys., 2009, 9, 8086.

49 A. L. Chong, J. I. Mardel, D. R. MacFarlane, M. Forsyth and A. E. Somers, ACS Sustainable Chem. Eng., 2016, 4, 17461755.

50 D. Prabhu, Int. J. ChemTech Res., 2013, 5, 2690-2705.

51 M. Yadav, S. Kumar, R. R. Sinha, I. Bahadur and E. E. Ebenso, J. Mol. Liq., 2015, 211, 135-145.

52 A. P. Hanza, R. Naderi, E. Kowsari and M. Sayebani, Eval. Program Plann., 2016, 107, 96-106.

53 P. Mourya, P. Singh, R. B. Rastogi and M. M. Singh, Appl. Surf. Sci., 2016, 380, 1-10.

54 A. Dada, A. Olalekan, A. Olatunya and O. Dada, IOSR J. Appl. Chem., 2012, 3, 38-45. 
55 E. A. Flores, O. Olivares, N. V. Likhanova, M. A. DomínguezAguilar, N. Nava and D. Guzman-Lucero, Corros. Sci., 2011, 53, 3899-3913.

56 S. E. Nataraja, T. V. Venkatesha and H. C. Tandon, Corros. Sci., 2012, 60, 214-223.

57 S. E. Nataraja, T. V. Venkatesha, H. C. Tandon and B. S. Shylesha, Corros. Sci., 2011, 53, 4109-4117.

58 S. Kumar, D. Sharma, P. Yadav and M. Yadav, Ind. Eng. Chem. Res., 2013, 52, 14019-14029.

59 K. Bhrara and G. Singh, Corros. Eng., Sci. Technol., 2007, 42, 137-144.

60 N. Zulfareen, K. Kannan, T. Venugopal and S. Gnanavel, Arabian J. Chem., 2016, 9, 121-135.

61 J. Vosta and J. Eliasek, Corros. Sci., 1971, 11, 223-229.

62 G. Gece, Corros. Sci., 2008, 50, 2981-2992.

63 N. Khalil, Electrochim. Acta, 2003, 48, 2635-2640.

64 M. A. Bedair, J. Mol. Liq., 2016, 219, 128-141.
65 T. Arslan, F. Kandemirli, E. E. Ebenso, I. Love and H. Alemu, Corros. Sci., 2009, 51, 35-47.

66 I. B. Obot, N. O. Obi-Egbedi and S. A. Umoren, Corros. Sci., 2009, 51, 276-282.

67 M. Yadav, D. Behera, S. Kumar and R. R. Sinha, Ind. Eng. Chem. Res., 2013, 52, 6318-6328.

68 M. Yadav, D. Behera, S. Kumar and P. Yadav, Chem. Eng. Commun., 2015, 202, 303-315.

69 M. Yadav, T. K. Sarkar and T. Purkait, J. Mol. Liq., 2015, 212, 731-738.

70 M. K. Awad, M. R. Mustafa and M. M. A. Elnga, J. Mol. Struct.: THEOCHEM, 2010, 959, 66-74.

71 M. Özcan, I. Dehri and M. Erbil, Appl. Surf. Sci., 2004, 236, 155-164.

72 H. Ju, Z. Kai and Y. Li, Corros. Sci., 2008, 50, 865-871.

73 G. Gece and S. Bilgic, Corros. Sci., 2009, 51, 1876-1878. 